\title{
Aspectos de la legislación clariana en las disposiciones capitulares del siglo XVI
}

\author{
M. ${ }^{a}$ Carmen García de la herrán muñoz
}

En rasgos generales se podría decir que el siglo XVI quedó marcado por la reforma en profundidad llevada a cabo en el ámbito eclesiástico, y sobre todo, lo que más nos interesaría, en el radio de acción franciscano. Entre las medidas más importantes que se tomaron se encontraba la adscripción a la Observancia, y la desaparición de la conventualidad, ya entrado el siglo, en el reinado de Felipe II. Los monasterios de monjas quedaban, así, bajo la jurisdicción de los franciscanos observantes. Para el mejor gobierno de la Orden, y evitar la autonomía de algunos conventos, se decretó la desaparición de la figura del Visitador ${ }^{1}$, centralizando la potestad, tanto de los conventos masculinos como femeninos, en la figura del Comisario General de la Orden y en los Superiores provinciales.

Por lo que a los monasterios de monjas se refiere, la reforma quedó marcada por la imposición por parte de la autoridad eclesiástica correspondiente, y con ayuda, en muchos casos, del brazo secular, del cumplimiento de la estricta clausura de las religiosas. Se reflejó la cuestión no sólo en las disposiciones capitulares, sino que obligó su cumplimiento las resoluciones del Concilio de Trento que abordaban los aspectos de la reforma monástica. Pero, además, se resolvieron otros temas no menos importantes para el mejor cumplimiento de la vida regular y del funcionamiento idóneo de los monasterios: el número de monjas que debía albergar; sus relaciones con los frailes, confesores o no; los bienes que debía poseer el convento y la gestión de los mismos; la oración y modo de comportamiento de las monjas; así como otras normas de carácter general que pusiesen de manifiesto la buena disposición de las religiosas.

En las disposiciones adoptadas en los Capítulos de Roma y Lyon de 1517 y 1518, respectivamente. 
Todos estos aspectos fueron expuestos en la normativa que, a parte de las bulas y disposiciones papales, emitieron los hermanos menores para las monjas que estaban bajo su jurisdicción. Quedaron recogidos en los Capítulos Generales que desde el de Terni, del año 1500, hasta el General de Valladolid, de 1593, se fueron reuniendo periódicamente. En la articulación de la Orden de Santa Clara jugaron un papel fundamental las resoluciones dictadas en los Capítulos celebrados en el siglo, ya que legislaron todos los aspectos que concernían a los monasterios de las religiosas de Santa Clara. Y así, a través de ellos, pueden seguirse, en bloques temáticos, los aspectos que más preocuparon a los legisladores para que las religiosas observasen el cumplimiento de la Regla, en una época en la que la costumbre y privilegios concedidos a través del tiempo habían llevado a muchos monasterios a la relajación de la observancia religiosa.

Jurisdicción. Desde el origen de la fundación de la Segunda Orden, Santa Clara, su fundadora, quiso acogerse al cuidado de los frailes menores. Sin embargo, el conseguir la jurisdicción que quería sobre sus religiosas fue desde el principio un tema conflictivo. Ya Gregorio IX, en 1222 , encomendó el cuidado de las monjas al ministro general; Inocencio IV, en 1247, las encomendaba al ministro general y provincial. En 1296, Bonifacio VIII obligó a cumplir las disposiciones de Inocencio IV. Tras una serie de vicisitudes, y ante la negativa de los frailes a hacerse cargo de las monjas, siendo ministro general San Buenaventura, se llegó a una solución concertada: los frailes no servirían a las monjas por obligación, siro por amor. A partir de este momento los componentes de la Primera Orden legislaron sobre todos los aspectos concernientes a la jurisdicción, y otras cuestiones, relativos a la Orden Segunda de la religión. Ya en el siglo XVI, en el Capítulo de Roma de 1517, se dispuso que los conventos de monjas quedasen bajo la jurisdicción del Capítulo General; pero también se dieron otras disposiciones para no aceptar más monasterios de religiosas bajo su cuidado, por no poderlas atender espiritualmente.

Capítulo General De Roma. $1517^{2}$ :

...los lugares, casas y monasterios de las monjas reformadas, según nuestras Letras ahora unidas, las que queremos estén sujetas al ministro general y ministros provinciales en sus provincias ${ }^{3}$.

2 Gubernatis, D. de, OFM, Orbis seraphicis. Vol. III. Pars. I., pág. 335. Las traducciones de los textos citados han sido realizadas por el P. Antolín Abad Pérez, OFM.

3 A partir de este decreto un elevado número de comunidades clarianas, incluidas las monjas coletinas, fueron puestas bajo la jurisdicción de los Observantes. 
Capitulo General de Niza. $1535^{4}$ :

Se determinó que no se acepte monasterio [de monjas] alguno sin antes obtener la licencia del Capítulo General o en cualquier caso del ministro general... ${ }^{5}$.

Visitador. Desde la fundación de la Orden de Santa Clara en el siglo XIII, la figura del Visitador se consolidó como un elemento básico en el funcionamiento de la misma. En España esta figura, que pasó a ser Visitador General, tomó un carácter autónomo y vitalicio ${ }^{6}$. Pero con los aires de reforma que corrían al empezar el siglo xvI, un personaje autónomo de esas características tenía que desaparecer y quedar sujeto a los superiores de la Orden. En los primeros años del siglo se legisló en este sentido. En 1517 se crearon las figuras del Comisario General y provincial que asumieron las funciones de los visitadores que habían existido hasta el momento; pero también delimitando sus obligaciones y modos de actuación en relación con los monasterios femeninos. En 1518 se decretó la desaparición del Visitador de monjas, citando explícitamente al monasterio de Tordesillas, aunque se siguió manteniendo el nombre en los que realizaban dichas funciones. No obstante, con la aplicación de los decretos del Concilio de Trento en 1565, la figura del Visitador especial de monjas llegó a desaparecer totalmente, ya que los monasterios quedaron adscritos a la jurisdicción de la orden regular o a la del obispo?.

Capítulo General De Roma. $1517^{8}$ :

Se ordena asimismo a las partes ultramontanas que todos los frailes que tienen cargo y cuidado de las religiosas estén sujetos a la obediencia

4 Gubernatis, D. de OFM, Op. cit. pág. 282.

5 A pesar de la normativa sobre la no fundación de nuevos conventos, el siglo xvi despuntó, dentro de la historia de la Orden de Santa Clara, por ser el que más fundaciones registró. Ejemplo de ello fueron las fundaciones del monasterio del Corpus Christi de Salamanca en 1541 y el de las Descalzas Reales de Madrid, en 1559, puestos ambos bajo la jurisdicción de los franciscanos observantes.

6 Véase lo referente al monasterio de Tordesillas. UnIVE, A., OFM. «Primer ensayo de la reforma franciscana en España. La congregación de Santa María la Real de Tordesillas», AlA 45 (85) $217-347$.

"Sesión XXV. De los Regulares y las Monjas. Capítulo IX. Gobierne el obispo los monasterios de monjas inmendiatamente sujetos a la Sede Apostólica; y los demás las personas nombradas en los Capítulos generales, u otros regulares".

Gobiernen los obispos, como delegados de la Sede Apostólica, sin que sirva de obstáculo inpedimento alguno, los monasterios de monjas inmediatamente sujetos a dicha Santa Sede, (...). Mas los que se gobiernan por personas nombradas en los capítulos generales, o por otros regulares, sigan al cuidado y custodia de los mismos. TEJADA Y RAMIRO, J., Colección de cánones y de todos los concilios de la Iglesia española. Madrid 1853. Vol. IV. págs. 419-420.

8 Gubernatis, D. de, OFM, Op. cit., pág. 237. 
de sus prelados de aquellos lugares o conventos y del ministro de aquella provincia; los visitadores, donde se tuvieren, sólo estén sujetos al comisario general, mientras no se disponga otra cosa.

Capítulo General De Lyon. $1518^{9}$ :

Iten mas, porque las clarisas, ya de la regla primera o ya de las Urbanitas, como así se las llama, como también otras cualquiera religiosas que estén bajo la obediencia nuestra, no tengan visitadores ni confesores elegidos por ellas, sino los que los ministros provinciales en sus capítulos nombraren; y los dichos visitadores y confesores, nombrados por sus provinciales con causas legítimas que deben ser conocidas y probadas por éstos y por algunos discretos del capítulo precedente, podrán ser visitador del tiempo legal del capítulo y ser privados de sus oficios. $Y$ deben dichos visitadores, confesores y los otros frailes que sirven a las religiosas, estar sujetos a los prelados de la Orden, como lo están los demás frailes. Puedan, no obstante, las predichas monjas, si así les pareciere, nombrar para visitador o confesor a algún fraile, a quién el ministro provincial con su definitorio, confirmar o instituir si les pareciere justo, no obstante los indultos apostólicos, privilegios y costumbres renovadas de los dichos monasterios, como son el caso de los monasterios de Tordesillas y Valencia, todos los cuales dejamos sin valor, anulados y revocados. Se entiende que los provinciales son los que deben asignar dichos cargos así a nuestras religiosas como a otras ${ }^{10}$.

Confesor. Como ocurrió con la figura del Visitador, el confesor fue un elemento importante en el desarrollo institucional y espiritual de los monasterios de la Segunda Orden. Ya en 1245, el papa Inocencio IV exhortaba a los frailes a que atendiesen a las monjas ${ }^{11}$. Norma que siguió

9 Ibidem, pág. 241.

10 Se hace mención expresa en este decreto a los monasterios de Santa María la Real de Tordesillas y al de la Puridad de Valencia. El caso del de Tordesillas está estudiado por el P. Uribe, véase nota $n^{\circ} 17$. Sin embargo, y a pesar de la resolución tomada en este Capítulo, hubo monasterios que no quisieron aceptar lo establecido; fueron los de la B.V. María de Zafra, el de la Concepción de Fregenal y el de la Madre de Dios de Llerena, los tres adscritos al régimen de Tordesillas, que acudieron al Papa solicitando el restablecimiento del visitador independiente. Lo que consiguieron con la ayuda de Don Juan Manuel, embajador de Carlos I en Roma, y que tenía en el monasterio de Zafra dos hermanas y una hija. MESEGUeR FeRnÁNDEZ, J., OFM, "Tres monasterios extremaños y el de Ipres (Bélgica) gobernados por visitadores a pesar del decreto de Lión de 1518", AlA, 12 (52) 366-372.

Poco después de estas fechas se promulgó el breve de León X, Cun sicut nobis, Roma, 17 3-1519, por el que el pontífice ordenaba bajo severas penas al provincial de Santiago que visitase por sí o por su comisario a los monasterios clarianos de Salamanca, Benavente, El Zarzoso, Oviedo y el de Concepcionistas de León, y que no se hiciese por medio del visitador. CASTRO, M. de OFM, "La provincia franciscana de Santiago. Ocho siglos de historia", Liceo Franciscano, 36 (83) 190-150.

11 En un documento de 16 de Octubre de 1245 dice: "oid las confesiones de las mismas, celebradles la misa y otros oficios divinos y administradles los sacramentos de la Iglesia». OMAECHEVARRíA, I., OFM, "La 'Regla' y las reglas en la Orden de Santa Clara», Sel. Fran 6 (77) 264. 
durante toda la historia de la Orden y que también Trento reflejó como obligación espiritual hacia las religiosas ${ }^{12}$. Pero en el plano temporal, por la conexión que estos hombres tuvieron con las religiosas, significaban un peligro en la vida cotidiana de los conventos, peligro que podía dar al traste con el cumplimiento de la clausura y otras normas conventuales. Por este motivo, fue una de las preocupaciones constantes en la normativa del período, por lo que sus obligaciones con las religiosas quedaron reflejadas de una manera exhaustiva con el fin de no poder transgredir la relación meramente espiritual que debían tener con las monjas.

Capítulo General De Terni. $1500^{13}$ :

...sólo al capellán con su socio le sea permitido visitar a las monjas, oir sus confesiones, $(\ldots)$.

Capítulo General De Telofani. $1532^{14}$ :

En la predicación de la palabra de Dios y administración de los Sacramentos o bien otras cosas que afectan al provecho espiritual, pongan todo cuidado y diligencia, pero en modo alguno y bajo las mismas penas entren en dichos monasterios, a no ser para administrar los Sacramentos; si algo hubiere de hacerse en dichos monasterios realícese por seglares y no por religiosos confesores o sus socios....

\section{Capítulo General De Niza. $1535^{15}$ :}

Tanto los guadianes como los confesores de monjas no excedan el trienio, que consideramos incoado a partir de esta Declaración...

\section{Capítulo General De Salamanca. $1553^{16}$ :}

Bajo la pena de anatema y de la maldición eterna mandamos a todos los confesores de las dichas monjas y a todos los prelados de nuestra orden que fuera de la mera y estricta necesidad y sólo en aquellos casos que la Regla y la autoridad apostólica lo conceden, la entrada a los citados monasterios, ya sea de la nuestra, ya de cualquier orden, que cuando hayan de hacerlo aquellos a quienes compete por su oficio y autoridad, lo hagan con la celeridad posible. (...).

\footnotetext{
12 Véase Tejada y Ramiro, J., Op. cit., pág. 420. Capítulo X, sobre el confesor extraordinario nombrado por el obispo para las monjas.

13 Gubernatis, D. de OFM, Op. cit., págs. 203-204.

14 Ibidem, pág. 277.

15 Ibidem, pág. 282.

16 Ibidem, págs. 341-342.
} 
Capítulo General De Roma. $1587^{17}$ :

Ningún fraile sea designado confesor de monjas o promovido, que no haya alcanzo los 40 años de edad y los 20 de vida religiosa, ni tampoco socios de los jóvenes, si no que han de ser ancianos, maduros y ejemplares. Los mismos confesores, terminado su bienio no sean mas a no ser que hayan vacado o cesado por un año íntegro, y otro tanto se dice de los socios, donde cómodamente se pueda hacer.

Abadesa. En el funcionamiento interno de los monasterios femeninos cobró verdadera importancia la figura de la abadesa ya que era la encargada de velar por el buen funcionamiento del mismo, tanto en el aspecto espiritual como en el material. Una de las preocupaciones de los legisladores fue el delimitar el tiempo que éstas debían ocupar el cargo, ya que ello dio lugar a que se formasen verdaderos grupos de poder dentro de los conventos, con el consiguiente daño que conllevaba en el mal cumplimiento de la Regia y en la relajación de las costumbres monacales que a la larga trajo consigo.

Desde el principio fue un cargo relevante en la organización del convento. Por eso las normas de elección, duración en el cargo, obligaciones, etc., quedaron bien delimitadas ${ }^{18}$. Sin embargo, su cumplimiento se fue mitigando conforme avanzó el tiempo, como ocurrió con otros aspectos reglares. En el siglo XVI se dictaron disposiciones capitulares que corroboraban toda la legislación anterior y cuyo culmen fue, por su importancia, las resoluciones tridentinas que obligaron de manera fehaciente a su cumplimiento ${ }^{19}$.

17 Ibidem, pág. 371.

18 Sobre el cargo de Abadesa, expuesto de un modo sintético, puede consuitarse OMAECHEvaría, I., OFM, "Evolución de estructuras en la Orden de Santa Clara», Sel. Fran. 2 (73) 145 .

19 «Sesión XXV. De la Reforma de Regulares y Monjas. Capítulo VII. Qué personas y de qué modo se han de elegir las abadesas, o superioras bajo cualquier nombre que lo sean. Ninguna sea nombrada para gobernar dos monasterios.

La abadesa y priora, prepósita, perfecta o la superiora, cualquiera que sea el nombre con que se la conozca, no será elegida menor de cuarenta años, debiendo haber vivido loablemente al menos ocho después de su profesión, y en caso de no hallarse monja con estas circunstancias en el mismo monasterio pueda eiegirse de otro de la misma orden. Mas si en esto aún hallase inconveniente el superior que preside la elección, elijase con consentimiento del obispo, $u$ otro superior, una del mismo monasterio que pase de treinta años, y ajustadamente haya vivido cinco por lo menos después de su profesión. Ninguna sea electa para mandar en dos monasterios; y si alguna obtiene en la actualidad de cualquier modo que sea dos o más, oblíguesela a que los renuncie todos dentro de seis meses a excepción de uno. Y si cumplido este término no lo hubiere verificado queden todos vacantes en derecho. El que presidiere la elec- 
Capítulo General De Laval. $1505^{20}$ :

También se ordena que todos los oficios de régimen de las tres órdenes de San Francisco sean trienales, tanto oficios generales, provinciales, y también guardianes, abadesas y maestras, y después de su trienio pueden ser elegidos para otro convento, pero no más de otro trienio...

\section{Capítulo General Intermedio De Burdeos. $1520^{21}$ :}

Iten, en la elección de la abadesa debe encontrarse siempre el ministro provincial acompañado de otro padre...

\section{Capítulo General De Paris. $1579^{22}$ :}

Las abadesas han de ser trienales; concluido su trienio no pueden ser reelegidas por otros tres años.

\section{Capítulo General De Roma. $1587^{23}$ :}

Las abadesas, acabado su trienio, por ninguna razón o suceso puedan tornar al mismo oficio, según el Decreto del Capítulo de París, sin antes haber pasado dos años desde el fin de su mandato ${ }^{24}$.

ción, sea obispo u otro superior, no entrará en los claustros del monasterio, sino que oirá, o tomará los votos de cada monasterio por la ventanilla de la reja. En todo to demás obsérvense las constituciones de cada orden o monasterio". TEJADA Y RAMIRo, J., Op. cit., pág. 417.

20 Gubernatis, D. de, OFM, Op. cit. pág. 213.

21 Ibidem, págs. 242-243.

22 Ibidem, pág. 335

23 Ibidem, pág. 369 .

24 Durante el siglo se observa que el cumplimiento de la Regla en cuanto al desempeño del cargo de abadesa se refiere no fue cumplido. En el monasterio de Santa Engracia de Pamplona, en la visita que en 1531 realizó el ministro provincial debido a los abusos de las religiosas clarisas, se constató que la abadesa llevaba ejerciendo el cargo ininterrumpidamente, veintiún años. SAgues, P., OFM. "Las clarisas de Pamplona y sus reformas en el siglo XVl», AlA 33 (73) 309.

En Santa Clara de Astorga, la abadesa Doña Catalina de Osorio, familia de los marqueses de Astorga, ocupó el cargo de 1524 a 1540 sin interrupción. CASTRO, M., de, OFM. «Monasterio de Santa Clara de Astorga", BRAH, 185 (88) 274.

En el monasterio de Estella, en el año 1539, la monja Juana Varrón consiguió el nombramiento de abadesa perpetua, dispensa de ser visitada por el provincial y de rendir cuenta de su administración a nadie. Todo esto trajo consigo una serie de graves acontecimientos en el convento. Goñl GazTAMBIDE, J., Historia eclesiástica de Estella. vol. II. Las órdenes religiosas. Pamplona 1990, pág. 243.

Doña Beatriz de Águila, tía del obispo de Zamora (1546-1560), Don Antonio del Águila, fue abadesa del monasterio de Santa Clara de Ciudad Rodrigo (Salamanca), cincuenta años. CAS TRO, M. de OFM. «La provincia franciscana...» pág. 232. 
Clausura. Bonifacio VIII por la bula Periculoso, de 1298, convirtió en ley el cumplimiento de la rigurosa clausura para todos los monasterios femeninos, sin embargo nunca se llevó a cabo de una manera estricta. En el movimiento reformista que se produjo en la centuria del XVI, la obligación del cumplimiento de la clausura era un objetivo primordial a llevar a cabo. Pero fue un gran obstáculo a salvar ya que su observancia prácticamente no se llevaba a efecto, y esto por diversos motivos, tales como las exenciones que tenían algunos monasterios sobre el particular - dispensas que quedaron reflejadas tanto en el permiso de entrada de seglares a los monasterios, o de salida de las monjas de ellos por motivos diversos-, o porque muchas congregaciones femeninas no habían aceptado esta norma monacal ${ }^{25}$. Toda la normativa referente a la clausura monacal, legislando tanto la entrada como la salida de los monasterios, llegó a su culmen con las disposiciones del Concilio de Trento, que decretó su cumplimiento estricto en todas las órdenes religiosas con instrucciones muy pormenorizadas ${ }^{26}$. No obstante todo lo dispuesto, el cumplimiento de la clausura fue difícil de observar y se convirtió en la máxima

25 El estudio de la reforma observante del período ha sido llevado a cabo, entre otros, por García Oro, J., "Conventualismo y Observancia", Historia de la Iglesia en España. La Iglesia en la España de los siglos xv y xvi. Vol. III-1 ${ }^{\circ}$. Madrid 1980, págs. 332ss.

${ }_{26}$ Sesión XXV. De la Reforma de Regulares y Monjas. "Capítulo V. Providencias acerca de la clausura y custodia de las monjas.

Renovando el santo Concilio la constitución de Bonifacio VIII, que principia Periculoso; mana a todos los obispos poniéndoles a la vista la divina justicia, y amenazándoles con la maldición eterna, que procuren con el mayor cuidaddo restablecer diligentemente la clausura de las monjas donde estuviere violada, y conservarla donde se observe, en todos los monasterios que les estén sujetos en virtud de su autoridad ordinaria y en los que no lo estén empleando la de la Sede Apostólica; refrenando a los inobedientes y a los que se opongan con censuras eclesiásticas y otras penas, sin embargo de cualquier apelación, e implorando también al efecto del auxilio del brazo seglar, si fuere necesario. El santo Concilio exhorta a todos los príncipes cristianos a que presten este auxilio, y obliga a ello a todos los magistrados seculares so pena de excomunión, ipso facto incurrenda. Ni sea lícito a ninguna monja salir de su monasterio después de la profesión, ni aun por breve tiempo, bajo ningún pretesto, a no mediar causa legítima que el obispo apruebe: sin que obsten cualesquier indultos ni privilegios. Tampoco sea lícito a persona alguna de cualquier clase, condición, sexo, o edad que sea, entrar en los claustros de un monasterio so pena de excomunión, en que se incurra por sólo el hecho, a no tener licencia por escrito del obispo o superior. Y sólo éstos la deben dar en casos necesarios y no ninguna otra persona de modo alguno, ni aun en virtud de cualquier facultad o indulto concedido hasta ahora, o que en adelante se conceda. Y por cuanto los monasterios de monjas, fundados fuera de poblado están espuestos muchas veces por carecer de defensas a robos y a otros insultos de hombres facinerosos; cuiden los obispos, y otros superiores, si les pareciere conveniente, de que se trasladen las monjas a otros monasterios nuevos o antiguos situados dentro de las ciudades o lugares bien poblados; invocando también para esto si fuere necesario, el auxilio del brazo secular. Y obliguen a obedecer con censuras eclesiásticas a los que lo impidan y no obedezcan". TEJADA Y RAMIRO, J., Op. cit., págs. 410-411. 
preocupación de los legisladores franciscanos ${ }^{27}$, preocupación que quedó reflejada en las disposiciones del momento.

Capítulo General De Terni. $1500^{28}$ :

$Y$ atiendan los superiores con toda diligencia para que las religiosas que les sean confiadas, observen la clausura, castigando a los transgresores con la maldición apostólica (...).

\section{Capítulo General De Asís. $1547^{29}$ :}

Las monjas que con autoridad del Sumo Pontífice salieran de su monasterio por cualquier causa, si luego quisieren volver no se las admita fácilmente; pero si se las admitiere, queden privadas de voz activa y pasiva y ocupen el último lugar en todos los monasterios para todos los asuntos de la casa y de las reuniones por dos años; la misma pena sea aplicada a las apóstatas que fueren readmitidas.

\section{Capítulo General De Salamanca. $1553^{30}$ :}

No se reciban señoras seglares en los monasterios de las monjas sin el mandato de la Santa Sede, ni tampoco niños o chicas en la infancia bajo pena de privación de los oficios locales (... ${ }^{31}$.

Frailes. Como los legisladores franciscanos quisieron desde un primer momento mantener un estricto cumplimiento de la clausura femenina, tuvieron que prohibir la conexión de las monjas con el mundo exterior. En este sentido, fue obvio que reglamentasen toda la relación que los propios religiosos de la Primera Orden debían tener con las clarisas, es decir, ninguna. Sólo permitieron la relación espiritual de las monjas con los confesores y visitadores, a todos los demás componentes franciscanos cualquier tipo de relación les estaba vedada, y no olvidaron dejarlo por escrito.

Capítulo General De Terni. $1500^{32}$ :

27 Sobre la mujer y la clausura en el período puede consultarse SÁnchez LoRA, J. L., Mujeres, conventos y formas de religiosidad barroca. Madrid 1988. VIGIL, M., La vida de las mujeres en los siglos XVI y XVII. Madrid 1986.

28 Gubernatis, D. de, OFM, Op. cit., págs. 202-208.

29 Ibidem, pág. 294.

30 Ibidem, págs. 341-342.

31 La Santa Sede permitió en muchas ocasiones el acceso de mujeres seglares a los monasterios, un ejemplo de ello lo tenemos en la concesión que sobre el particular hizo a la Marquesa de Astorga, Doña Mencía Osorio Quiñones, que le concedió el privilegio de poder vivir dentro del convento, aunque parece ser no usó de él. CAStro, M. de, OFM., «Monasterio de Santa Clara de Astorga»..., pág. 280.

${ }^{32}$ Gubernatis, D. de, OFM, Op. cit., págs. 202-208. 
(..) que los frailes no ingresen en los monasterios de monjas y que por el nombre de monasterio entendemos el claustro, las casas y las oficinas interiores: pues a otros lugares que se refieren a los seglares, puedan los frailes por razón de predicación o de pedir limosna, si para ello tuvieren licencia de los superiores, entrar, siempre que se les haya concedido considerada su madurez e idoneidad;... si alguno sin esa licencia se atreviere a llegar a cualquiera de los dichos monasterios, por el mismo hecho sea encarcelado...

\section{Capítulo General De Telofani. $1532^{33}$ :}

Prohíbanse con todo rigor los accesos de los frailes a los monasterios de tales religiosas y hermanas, y que no puedan hablar con ellas sin la licencia 'in scriptis' del ministro provincial aunque por razón de hospitalidad y por la celebración [de misas] se pueda acudir a ellos siempre que no haya conventos de frailes menores.

\section{Capítulo General De Asís. $1547^{34}$ :}

Se ordena que ningún fraile pueda acercarse al monasterio de monjas si no es urgiendo grave necesidad, que ha de ser provada por el provincial y otro padre grave.

\section{Capítulo General De Roma. $1571^{35}$ :}

Que los frailes no coman en los monasterios no hablen con alguna religiosa, aún en días festivos en que se celebran solemnidades de las monjas...

Bienes. La Reforma no sólo actuó en los aspecto espirituales de los monasterios, sino que lo hizo también en los crematísticos. Un grave problema constatado era la falta de medios económicos de los conventos para su buen funcionamiento ${ }^{36}$; lo que traía como consecuencia la rela-

33 Ibidem, pág. 277.

34 Ibidem, pág. 293-294.

35 Ibidem, pág. 356.

${ }^{36}$ Una fuente importante de ingresos en los monasterios de la Segunda Orden fueron las donaciones, tanto de carácter particular como real. En este sentido encontramos: «Al margen: Merced de los bienes de Violante Caruallo, beata, a la orden de Sant Francisco:

En el dicho mes de enero del dicho año (1511) con acuerdo de los ss. del dicho consejo de su alteza fizo merced de todos los bienes asi muebles como raizes de Violante, beata, vezina de la cibdad de Cuenca, muger que fue de Caruallo, a la orden de Sant Francisco para que con que substenten la dicha beata reconciliada e condenada a carcel perpetua, y esto por su vida de la dicha Violante, e después de su vida fizo merced su alteza de los dichos bienes por 
jación de las costumbres, ya que no era extraño que las religiosas se dedicasen a la mendicidad, dejando así de practicar la clausura. Uno de los motivos de esta situación era el elevado número de monjas que residían en los conventos. Con al fin de atajar dicha anomalía, desde las primeras décadas del siglo se dieron normativas para que el defecto se corrigiese. En 1518 el ministro general Licheto ordenó que no se aceptasen monasterios cuyas rentas no pudiesen mantener a cincuenta religiosas ${ }^{37}$. El Concilio Tridentino también resolvió en este asunto ${ }^{38}$. Breves papales posteriores al Tridentino quisieron remediar este mal ${ }^{39}$, pero no se consiguió resolver hasta bien entrado el siglo XVII. Además de estas cuestiones, no se olvidaron los Capítulos Generales de dar instrucciones sobre el modo de gestionar los bienes conventuales.

Capitulo General De Terni. $1500^{40}$ :

iguales partes a los monasterios de Sant Francisco de Alcaraz e al monasterio de monjas de la villa de Alcecer que se dize [de santa Clara?]». - Libro 572 de la Sección de Inquisición del A.H.N., fol. 196 v., citado por MESEguer FERNÁNDEZ, J., OFM, "Documentos históricos diversos. III. El Cardenal Cisneros, inquisidor general», AlA, 43 (83) 145

${ }_{37}$ Desde el origen de la Orden la cuestión de los bienes de los monasterios fue una preocupación constante para los legisladores. En un primer momento, en 1218, los monasterios aparecieron sin posesiones ni rentas; pero ya en 1228, Gregorio IX concedió la autorización para poseer bienes estables. A partir de aquí diferentes papas, entre ellos Urbano IV, con la emisión de la Segunda Regla, consolidó la tendencia a poseer rentas y posesiones. Se llegó así a las disposiciones de Benedicto XIII, Estatutos Benedictinos, de 1336, donde se reafirmó y legitimó la posesión de bienes cuantiosos, incluso se dieron indultos para que las monjas pudiesen tener sus propios bienes. OMAECHEVARRIA, I., OFM, «Evolución de estructuras...”, págs. 136-137.

38 Consúltese Garcia Oro, J., Op. cit., págs. 333-334. Iriarte, L., Historia Franciscana. Valencia 1975, pág. 495. Jedin, H., Historia del Concilio de Trento. Pamplona 1980, pág. 264. Sesión XXV. De la Reforma de Regulares y Monjas. "Capítulo II. Prohíbese absolutamente a los regulares la propiedad.

Ningún regular de cualquier sexo pueda poseer o tener como propios, ni aún a nombre del convento, bienes muebles, ni raices, de cualquier calidad que sean, ni de cualquier modo que los haya adquirido, sino que se deben entregar inmediatamente al superior e incorporarse al convento. Ni sea permito en adelante a los superiores conceder a religioso aiguno bienes raices, ni aún en usufructo, uso, administración o encomienda. Pertenezca pués la administración de los bienes de los monasterios, o de los conventos solo a los oficiales de estos, los que seran amovibles a voluntad del superior. $Y$ el uso de los bienes muebles ha de permitirse por los superiores en términos, que corresponda al ajuar de sus religiosos al estado de pobreza que han profesado: nada haya superfluo en su menaje; más tampoco se les niegue nada de lo necesario. $Y$ si se hallare o se convenciere a alguno de poseer algo en otros términos, quede privado por dos años de voz activa y pasiva, y castíguesele además según las constituciones de su regla y orden. TeJAdA y RAmiRo, J., Op. cit., pág. 404-405.

39 Para adecuar el número de religiosas a las posibilidades económicas del monasterio, se emitió el breve De statu ecclesiarum, de 7 de octubre de 1568, que se volvía a reiterar el 1 de octubre de 1571.

40 Gubernatis, D. de, OFM, Op. cit., págs. 205-207. 
Ordenamos que así las abadesas como otras u otros que luego hayan de administrar esos bienes, las que los reciben o expenden, estén obligadas a dar cuenta precisa a las personas discretas elegidas por los monasterios de las cosas recibidas y gastadas y de aquellas que se les deben, como del estado en que se encuentra el monasterio.

Capítulo General De Roma. $1571^{41}$ :

Que observe el Canon del Concilio [de Trento] sobre los bienes particulares.

Número de componentes conventuales. Como se ha comentado en el apartado precedente, el número de monjas debía estar en consonancia con los bienes del monasterio, o viceversa, ya que una cuestión llevaba a la otra. La legislación franciscana siempre fue muy explícita en este punto, y así, ya quedó recogido en las Ordenaciones de Benedicto XIII, de 1336, que ordenaban se marcase el número de monjas a recibir en un monasterio según sus posibilidades económicas. En 1500, por medio de los Estatutos Alejandrinos, se vuelve a recoger lo establecido, para llegar así a las disposiciones del Ministro General Licheto, ya comentadas, y la normativa que trajo el siglo XVI, entre la que habría que destacar, con carácter general, la disposición Tridentina sobre el número de componentes conventuales y los bienes a poseer el monasterio en relación con ellos ${ }^{42}$.

Capítulo General De Terni. $1500^{43}$ :

41 Ibidem, pág. 356.

42 Sesión XXV. Reforma de los Regulares y Monjas. "Capítulo III. Todos los monasterios a excepción de los que aquí se mencionan, pueden poseer bienes raices: débeseles asignar número de individuos según sus rentas, o en proporción a las limosnas que reciben; no se erija ninguno sin licencia del obispo.

El santo Concilio concede que puedan poseer en adelante raices todos los monasterios y casas asi de hombres como de mugeres, e igualmente de los mendicantes, a excepción de los conventos de capuchinos de San Francisco, y de los que se llaman menores observantes, aun aquellos a quienes o estaba prohibido por sus constituciones, o no les estaba concedido por privilegio apostólico. Y si algunos lugares de los referidos se hallasen despojados de semejantes bienes que lícitamente poseían con permido de la autoridad apostólica, decreta que todos se les deban restituir. Mas en los monasterios y casas mencionadas de hombres y mugeres, posean o no bienes raices, solo se ha de establecer y mantener en adelante aquel número de personas que se puedan sustentar comodamente con las rentas propias de los monasterios, o con las limosnas acostumbradas; ni en adelante se han de fundar semejantes casas, a no obtener antes la licencia del obispo, en cuya diócesis se han de establecer. TEJADA Y RAmiro, J., Op. cit., pág. 406.

43 Gubernatis, D. de, OFM., Op. cit., pág. 204. 
Nosotros determinamos sobre las casas o monasterios, si es que están bajo la obediencia y el cuidado de los frailes menores, o estarán en un futuro de la orden de Santa Clara o de San Damián o de cualquier otro nombre con que sean conocidas, queriendo proveer... que en cada uno de los dichos monasterios, ya por los ministros provinciales con el consentimiento de la abadesa o del mayor número de sus religiosas, se fije cierto número de religiosas a tenor de las posibilidades económicas para que así puedan sustentarse dignamente y que en modo alguno sea permitido aumentar esa tasa o cifra, si no fuere con autoridad apostólica o licencia especial o también porque aumentaren esas bases de sustentación y se pueda alimentar a mayor número (...), no se haga innovación si no es con la licencia del ministro general o provincial... ${ }^{44}$.

Normas generales. Los frailes menores observantes que tenían bajo su jurisdicción a las monjas de Santa Clara y hermanas de la Tercera Orden no dejaron de legislar durante todo el período tratado sobre los agentes externos - visitadores, confesores, frailes, seglares, etc.- que podían influir en el incumplimiento de la observancia por parte de las religiosas, que iría en detrimento de la vida espiritual de los monasterios. Pero, además, reglamentaron todos los aspectos de la vida cotidiana de los conventos, para así, conseguir que la tan ansiada reforma monacal que se quería implantar tuviese un efecto positivo y acabar con el grado de relajación que se había ido implantando en las casas conventuales.

\section{Honestidad.}

\section{Capítulo General De Terni. $1500^{45}$ :}

Se manda asimismo a los ministros, bajo la misma pena; que quiten a las monjas todo ornato indecente en los vestidos $u$ otras cosas no convenientes y que todas se conformen con el hábito gris y la forma establecida; cuyos hábitos se cierren hasta el cuello, para que no se manifieste indencencia alguna, que tenga las mangas largas, según lo pide la antigua costumbre de la religión y de la honestidad.

$Y$ si alguna andare con el pecho descubierto, los cabellos largos y sueltos o bien pintada con colores y aceites, y amostada no se corrigiere, sea privada del velo y del acceso a las rejas por tres meses; y si esta vez tampoco se enmendare, no se le devolverá a su antiguo estado.

44 Aunque existía la normativa para controlar el número de monjas que debía albergar un monasterio, siempre hubo privilegios que mitigaban el cumplimiento de esta resolución. Así pues, la reina Isabel la Católica consiguió del Papa Alejandro VI el breve Singularis Devotionis, de 28 de agosto de 1497, por el cual las damas de la reina que estimaran convenientes podían ingresar en el monasterio de Calabazanos, que no podía sobrepasar el de cincuenta religiosas. A pesar de ello, el 5 de noviembre de 1501, la reina escribe a la abadesa, enviándole copia del citado breve, para que admitiese en su comunidad a Doña María de Portocarrero. MESEGUER FERNÁNDEZ, J., OFM, “Un breve de Alejandro VI y una carta de Isabel la Católica», AIA, 9 (49) 379-383.

45 Gubernatis, D., de, OFM, Op. cit., págs. 206-207. 
Locutorio.

Capítulo General De Terni. $1500^{46}$ :

Se manda también a los ministros, bajo pena de privación del cuidado de dicho monasterio, que ordenen, bajo la pena de privación de velo y con las otras penas y censuras, que ninguna monja pueda hablar con otra secular, aunque se trate de sus consanguíneas sin la presencia de la Abadesa o de otra monja anciana y de buena fama para esto destinada.

Capítulo General De Salamanca. $1553^{47}$ :

Ninguna Abadesa o cualquier otra religiosa o hermana hablen con seglares si no están acompañadas de dos o tres hermanas maduras y de las más antiguas y les oigan, bajo pena de una disciplina que se hará en comunidad por la primera vez...

\section{Dormitorio.}

Capítulo General De Terni. $1500^{48}$ :

"También prohibimos que las monjas tengan habitaciones o celdas en sus dormitorios; si existieran algunas deben ser destruidas inmediatamente por los ministros o visitadores en la inmediata visita que hicieren; (...)

Se ordena... que todas las monjas, como lo manda la Regla, duerman en sala común, como ya fue dicho por la Constitución de Benedicto ${ }^{49}$; y que tal dormitorio sea amplio y cerrado. Y si algunas, por contumacia, durmieren fuera, sean destruidas esas habitaciones por el ministro, (...)

Normas varias.

Capítulo General De Terni. $1500^{50}$ :

Se prohibe a las monjas mantener perros grandes, pero también que se eviten los pequeños en abundancia.

\section{Capítulo General De Roma. $1571^{51}$ :}

46 Ibidem, págs. 206-207.

47 Ibidem, 341, 343.

48 Ibidem, págs. 206-207.

49 Constituciones u Ordenaciones de Benedicto XIII, dadas en 1336.

50 Gubernatis, D., de, OFM, Op. cit., págs. 206-207.

51 Ibidem, pág. 356. 
Que las monjas conversas no puedan ser elegidas para otros oficios que para la cocina y los que se llamaba de servicio, que no exigen o son dignidad.

Además de las disposiciones capitulares emitidas por los religiosos de la Primera Orden, se dictaron también en dichos Capítulos - Intermedio de Toledo de 1583 y General de Valladolid de 1593 - unas Constituciones - Estatutos que pormenorizaban las obligaciones de las monjas para el cumplimiento de la observancia regular. Sin embargo, y a pesar de la preocupación constante que mantuvieron los frailes para que la Regla fuese observada, sobre todo en un tema tan importante como era el relativo al acatamiento de la clausura - preocupación no sólo del ámbito religioso sino también del civil, como lo pondrían de manifiesto las actuaciones de Carlos I y Felipe II $^{52}$-, en el siglo XVI no lo consiguieron. En la centuria siguiente se volvió a legislar sobre las mismas cuestiones, pero tampoco entonces iograron lo que tan arduamente se habían propuesto: que las religiosas de la Segunda Orden de Santa Clara cumpliesen la estricta observancia de la Regla.

52 García Oro, J., Op. cit., pág. 332ss. 